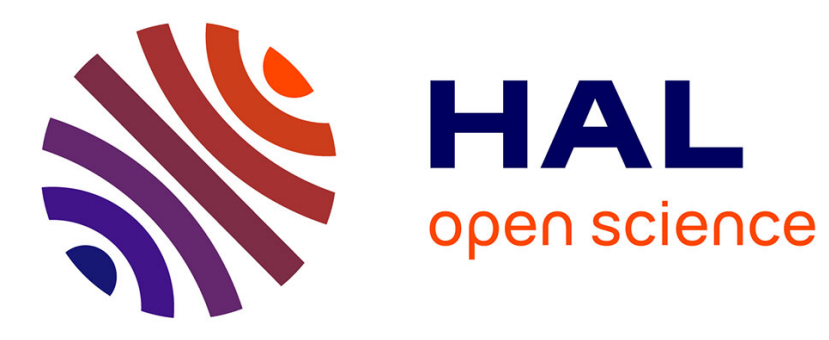

\title{
Reconstructing the geographic and climatic origins of long-distance bird migrations
}

Paul Dufour, Sébastien Descamps, Stéphane Chantepie, Julien Renaud, Maya Gueguen, Katja Schiffers, Wilfried Thuiller, Sébastien Lavergne

\section{- To cite this version:}

Paul Dufour, Sébastien Descamps, Stéphane Chantepie, Julien Renaud, Maya Gueguen, et al.. Reconstructing the geographic and climatic origins of long-distance bird migrations. Journal of Biogeography, 2020, 47, pp.155 - 166. 10.1111/jbi.13700 . hal-02415042

\section{HAL Id: hal-02415042 \\ https://hal.science/hal-02415042}

Submitted on 12 Nov 2020

HAL is a multi-disciplinary open access archive for the deposit and dissemination of scientific research documents, whether they are published or not. The documents may come from teaching and research institutions in France or abroad, or from public or private research centers.
L'archive ouverte pluridisciplinaire HAL, est destinée au dépôt et à la diffusion de documents scientifiques de niveau recherche, publiés ou non, émanant des établissements d'enseignement et de recherche français ou étrangers, des laboratoires publics ou privés. 


\title{
Reconstructing the geographic and climatic origins of long-distance bird migrations
}

\author{
Paul Dufour $^{1}$ (i) | Sébastien Descamps ${ }^{2}$ (D) | Stéphane Chantepie ${ }^{3}$ | Julien Renaud ${ }^{1}$ | \\ Maya Guéguen $^{1}$ | Katja Schiffers ${ }^{4,5}$ | Wilfried Thuiller ${ }^{1}$ (D) | Sébastien Lavergne ${ }^{1}$
}

${ }^{1}$ Univ. Grenoble Alpes, CNRS, Univ. Savoie Mont Blanc, LECA, Laboratoire d'Écologie Alpine, F-38000 Grenoble, France

${ }^{2}$ Fram Centre, Norwegian Polar Institute, Tromsø, Norway

${ }^{3}$ Department of Evolutionary Biology and Environmental Studies, University of Zürich, Zurich, Switzerland

${ }^{4}$ Senckenberg Biodiversity and Climate Research Centre (BiK-F), Frankfurt (Main), Germany

${ }^{5}$ INRES, University of Bonn, Bonn, Germany Correspondence

Paul Dufour, LECA, UMR UGA-USMB-CNRS 5553, Université Grenoble Alpes, CS 40700 38058 Grenoble Cedex 9, France.

Email: paul.dufour80@gmail.com

Funding information

LabEx OSUG@2020, Grant/Award Number: ANR10LABX56

Handling Editor: Dr. Damaris Zurell

\begin{abstract}
Aim: Seasonal bird migration is one of the most fascinating global ecological phenomena. Yet, the biogeographic scenarios and climatic drivers that led single species or entire lineages to evolve seasonal migration between disjunct breeding and wintering ranges remain unclear. Based on distribution and phylogenetic data for all birds worldwide, we explored the biogeographic and climatic context of the evolutionary emergence of seasonal geographic migration in birds.

Location: Global.

Taxon: The Aves class (9,819 species).
\end{abstract}

Methods: We used the worldwide phylogeny of all birds, with a new backbone tree, to test the link between birds' migration distance (short, variable, long) and strategy (resident, mixed, strict migrant) with four different metrics depicting species' thermal niches in their breeding and wintering ranges. We also performed ancestral state reconstructions for the main migratory orders to reconstruct past events of appearance and loss of migration behaviour, and past biogeographic scenarios that led to the emergence of seasonal geographic migration.

Results: Migratory species generally experience warmer climates in their wintering range compared to their breeding one, although notable exceptions exist. This thermal niche change due to migration was found to be much larger for species travelling large distances. We also found that geographic migration emerged at different time periods through varied biogeographic paths (i.e. both from temperate and tropical ancestors) and that migration behaviour was likely ancestral to Passeriformes, with several subsequent episodes of loss of migration behaviour.

Main conclusions: We report an evolutionary correlation between long-distance migration and the tendency of birds to seek warmer climates during their non-breeding period, compared to short-distance migrants. Migration behaviour was likely ancestral to Passeriformes, and migratory lineages in general seem to have often adapted to novel ecological opportunities by returning to a resident state. Our results provide the first large-scale study of biogeographic and climatic origins of bird migration worldwide.

\section{KEYWORDS}

ancestral state reconstructions, biogeographic scenarios, bird migration, climatic niche conservatism, migration distance, phylogenetic comparative methods 


\section{1 | INTRODUCTION}

Birds undertake some of the most spectacular annual migrations in the animal kingdom, with several billions of birds travelling twice a year, sometimes over tens of thousands of kilometres between their breeding and wintering grounds (e.g. Egevang et al., 2010). This phenomenon of geographic disjunction between the breeding and wintering ranges of certain species has long invited investigations regarding the physiology, behaviour and navigation of migratory birds (see Alerstam, Hedenström, \& Åkesson, 2003; Gwinner \& Helm, 2003; Newton, 2008; Pulido, 2007). Yet, the conditions that triggered the evolution of seasonal migration behaviour remain poorly understood, and seem to include both abiotic and biotic drivers, such as seasonal habitat quality and trophic resources, escape from predators, pathogens or competitor avoidance (Alerstam et al., 2003; O'Connor, Cornwallis, Hasselquist, Nilsson, \& Westerdahl, 2018; Somveille, Rodrigues, \& Manica, 2018).

A largely documented biogeographic pattern is the tendency of most migratory birds to breed in regions characterized by strongly seasonal environments (Somveille, Rodrigues, et al., 2015, 2018). A recent paper (Winger, Auteri, Pegan, \& Weeks, 2019) reviewed the studies that attempted to integrate theories about the evolution of bird migration with the biogeographic history of migratory clades (Louchart, 2008; Salewski \& Bruderer, 2007; Winger, Barker, \& Ree, 2014; Zink, 2002) and stressed that the biogeographic origins of bird migration have rarely been considered in relation to the onset of climatic seasonality. They further called for a change of perspective towards viewing the evolution of bird seasonal migrations as an adaptation for long-term persistence in seasonal environments. Consequently, understanding the biogeographic and climatic drivers that triggered the emergence of bird migration requires an examination of the year-round climatic niches in their breeding and wintering ranges, in relation to different birds' migratory strategies. Considering a global scale and comparing major migratory bird clades can help shed additional light on this phenomenon.

Recent works suggested that the year-round climatic conditions experienced by migratory birds can show two distinct patterns, which have been termed 'niche tracking' and 'niche switching' strategies (e.g. Gomez, Tenorio, Montoya, \& Cadena, 2016; Laube, Graham, \& Boehning-Gaese, 2015; Zurell, Gallien, Graham, \& Zimmermann, 2018). First, seasonal migration may allow birds to track similar climates through time ('niche tracking' hypothesis) due to relatively narrow environmental tolerances (Gomez et al., 2016; Zurrell et al., 2018). Indeed, some migratory birds tend to exploit overlapping climatic niches in their breeding and wintering ranges (Somveille, Manica, \& Rodrigues, 2018). Other migratory birds tend to spend winter in a different climate than that of their breeding range ('niche switching', e.g. Joseph \& Stockwell, 2000; Laube et al., 2015; Nakazawa, Peterson, Martínez-Meyer, \& Navaroo-Siguenza, 2004). This would be particularly expected when migrating towards a warmer environment is associated with a greater resource supply or lower pathogen avoidance (Alves et al., 2013, 2011), or more broadly when an adjustment of breeding ranges is favoured during evolution
(Martínez-Meyer, Peterson, \& Navarro-Sigüenza, 2004). It remains unknown, however, which of the two patterns of niche tracking and switching generally applies, whether there are differences between clades and associations with particular features of migratory species, in particular migration distance. For example, a recent study suggests that bird species travelling intermediate distances would be the most likely to track their climatic niche (Somveille, Manica, et al., 2018).

Traditional paradigms to explain the emergence of bird migration are based on the geographic origin from which the migration evolved, although this region of origin does not need to be the same as the biogeographic origin of a lineage (Bruderer \& Salewski, 2008; Salewski \& Bruderer, 2007). The most widely accepted 'southernhome' theory (SHT hereafter) proposes that long-distance migrants evolved from resident tropical species through the poleward shift of their breeding ranges, in order to avoid competition and exploit summer resource peaks in temperate latitudes (Cox, 1968; Gauthreaux, 1982; Levey \& Stiles, 1992; Rappole, 1995). Alternatively, the 'northern-home' theory (NHT hereafter) stipulates that migration evolved from resident temperate species at higher latitudes, shifting their wintering grounds to lower latitudes to escape adverse winters (Bell, 2000; Gauthreaux, 1982). The latter scenario assumes greater fitness benefits when migrating towards lower latitudes (as shown in Alves et al., 2013), but it does not necessarily imply tracking of the same climatic niche year-round. Thus far, no consensus has emerged to explain the biogeographic origins of seasonal bird migrations (see also Louchart, 2008; Salewski \& Bruderer, 2007; Winger et al., 2019). We suggest that the support of either of these two hypotheses may mostly depend on the evolutionary history of the clades under consideration (see Winger et al., 2014 for Emberizoidea).

In this study, we explored the biogeographic and climatic context of the evolutionary emergence of seasonal geographic migration in birds worldwide. To do so, we merged two recent phylogenies of all extant bird species and characterized the geographic range information of all migratory birds. We tested whether species migration distances (short, variable, long) and strategies (resident, mixed, strict migrant) are linked to the seasonality of their breeding range and to their tendency to track their thermal niches through seasons ('niche tracking' vs. 'niche switching'). We also reconstructed the temporal and biogeographic scenario under which seasonal geographic migration evolved in major migratory bird orders (NHT vs. SHT), by retracing the biogeographic origin of the lineages that have developed migration behaviours. To identify general patterns, we first based our study on a global scale (9,819 species). Then, to confirm the generality of these patterns, we focused on three orders accounting for most of the world's migratory species, including the longest migrants (see Figure 1a): the orders of Anseriformes (160 species), Charadriiformes (368 species) and Passeriformes (5,895 species). We employed this hierarchical approach because the emergence of seasonal migration behaviour is likely a complex phenomenon influenced by the specific ecological and evolutionary context of the particular clade. Few studies have so far explored and test the evolutionary links between birds' climatic niches, geographic distributions 


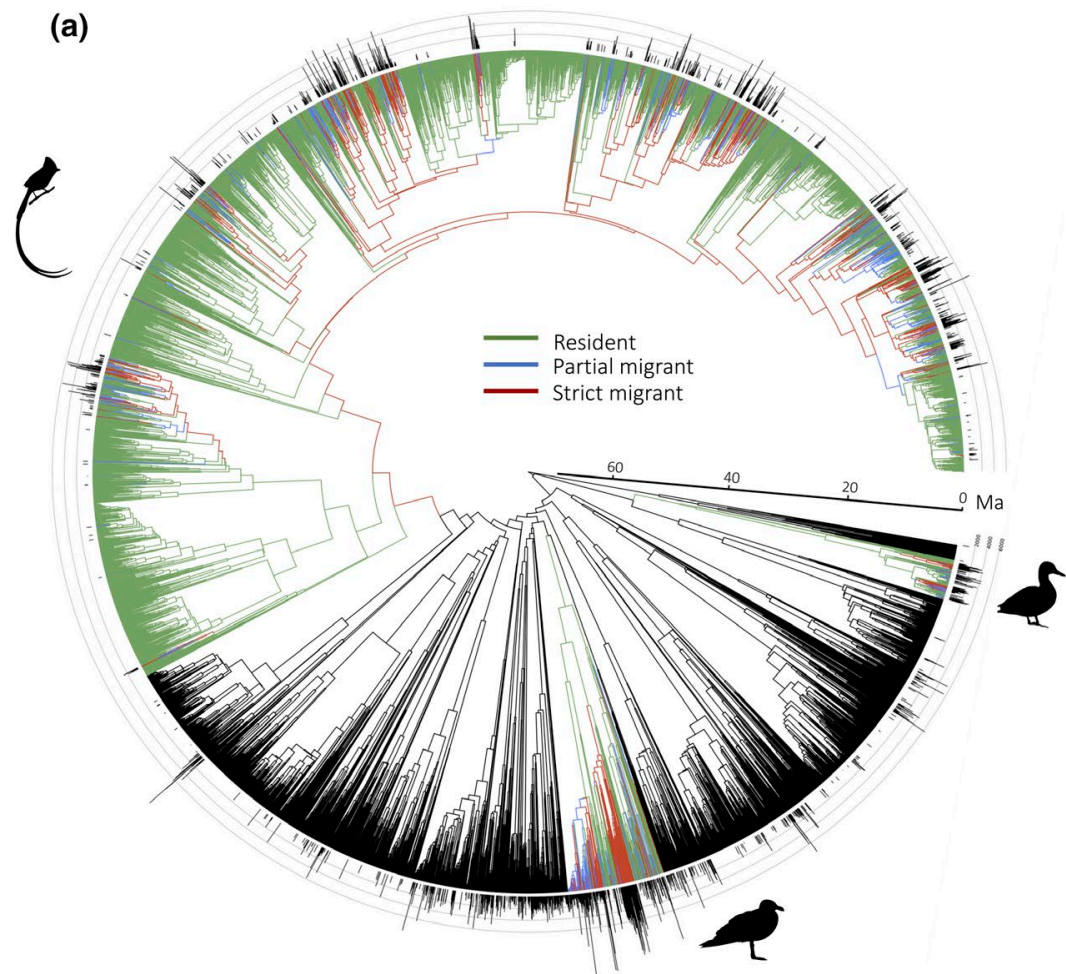

(b)
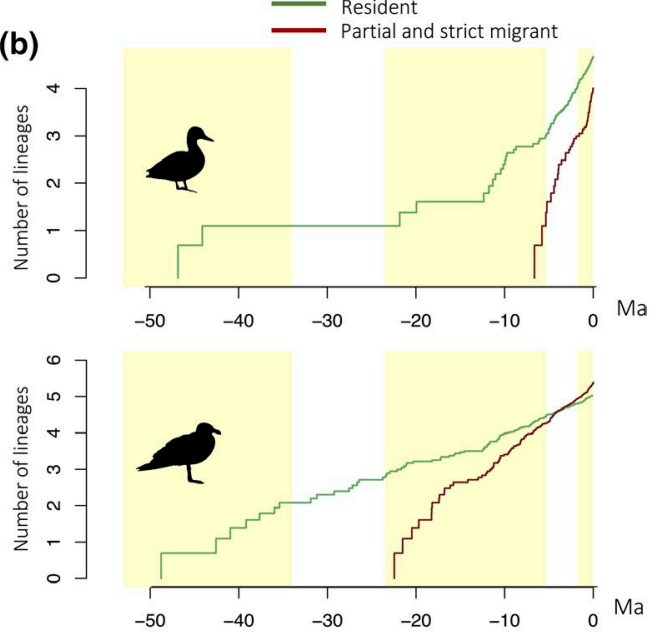

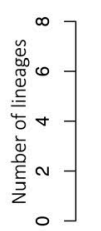

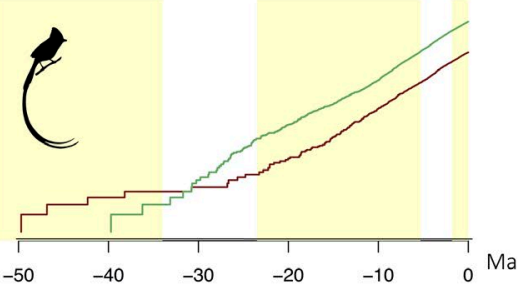

FIGURE 1 Reconstruction of ancestral migratory strategies and their temporal accumulation across the global bird phylogeny and the three study orders, Anseriformes, Charadriiformes and Passeriformes. (a) The phylogeny's edges are coloured based on the reconstructed ancestral migration strategies, as follows: green for resident species, blue for partial migrants and red for strict migrants. Edges from species not belonging to the three study orders are in black. Black lines in front of the tip labels depict a quantitative estimate of distance of geographic migration for each species (considered null for resident species). (b) Lineage-through-time plots depicting the temporal accumulation of migratory and resident species (red and green lines, respectively). Partial and strict migrants were grouped together. Ancestral migratory behaviours were assigned to each node based on the marginal likelihood values. Yellow and white shading highlights important geological eras, namely Eocene (-56/-34 Ma), Oligocene (-34/-23 Ma), Miocene (-23/-5.3 Ma), Pliocene (-5.3/-2.6 Ma) and Pleistocene-Holocene (-2.6 Ma to present) [Colour figure can be viewed at wileyonlinelibrary.com]

and different migratory characteristics, both at a global scale and within major orders of migratory birds.

\section{2 | MATERIALS AND METHODS}

\section{1 | Species ranges, climatic niches, migration strategies and phylogeny}

Breeding, resident, and wintering distribution ranges of all bird species were collected from Birdlife International and NatureServe (2017) and gridded at a 10-min resolution after substantial corrections and recoding for some bird groups (see Appendix S1). Such a high spatial resolution was necessary to depict the climatic niches of species having particularly narrow and fragmented breeding ranges, which is typical for many colonial migrants nesting in insular environments. As the climatic niche of a single cell may not reflect the climate experienced by narrow-ranging species, we removed species with distributional ranges smaller than the size of a grid cell (omitted species listed in Appendix S1). In total, we considered 9,819 species out of the 9,993 species recognized in Jetz, Thomas, Joy, Hartmann, and Mooers (2012). The mean temperature of each grid cell was calculated for both boreal and austral location and for both winter and summer time periods, which we call temperatures of breeding and wintering ranges hereafter (Appendix S1). For reasons of data availability, we made the choice to assign northern summer to all breeding ranges above the equator (and vice versa for the Southern hemisphere) without considering the few species that may not fully follow this pattern.

Movement information was taken from standard reference handbooks (e.g. del Hoyo, Elliott, Sargatal, Christie, \& Juana, 2018). To deviate from the oversimplified binary view of bird migration ('migrant' vs. 'non-migrant'), we distinguished three strategies: strict migrants (784 species), for which all individuals move to a wintering range geographically disjunct from the breeding one; partial migrants (813 species), for which the species consists of a strict migrant and resident fraction; and residents (8,222 species), for which all populations occur year-round within their breeding range (Rappole, 2013). Defining avian migration as a regular, endogenously controlled, seasonal return movement of birds between breeding and non-breeding areas (Salewski \& Bruderer, 2007), we assumed that most tropical species fall into the resident category, even if facultative migration (Winger et al., 2019) and dispersal movements of these tropical 
species may have implications on the evolution of migratory behaviour (see details in Appendix S1).

For migratory species (strict and partial), we defined three classes of migration distance from distribution maps and reference handbooks (del Hoyo et al., 2018). We defined (a) short-distance migrants as species travelling to a wintering site within $2,000 \mathrm{~km}$; (b) long-distance migrants as species travelling more than $2,000 \mathrm{~km}$; and (c) variable-distance migrants as species with some populations travelling less than 2,000 km and some more (Rappole, 2013). Overall, 620 species were classified as short-distance migrants, 576 species as variable-distance migrants and 401 species as long-distance migrants. A quantitative value of the distance of migration was calculated from range maps to support the categorization by testing whether our categorical and quantitative measurements of migration distance showed a consistent relationship (see details in Figure S2.2 in Appendix S1).

To base our study on the most up to date worldwide avian phylogeny, we merged two phylogenies by constructing a composite of the new phylogeny of birds recently established by Prum et al. (2015) and the maximum clade credibility (MCC) tree from Jetz et al. (2012), following the method described in Cooney et al. (2017; see details in Supporting Information). We also pruned all trees from the Prum MCC posterior distribution to generate trees for the three study orders (i.e. Anseriformes, Charadriiformes and Passeriformes).

\section{2 | Climatic data}

Monthly averages of mean air temperatures (from 1960 to 1990) were extracted from the WorldClim database (Hijmans, Cameron, Parra, Jones, \& Jarvis, 2005) at a 10 -min resolution $(18.5 \mathrm{~km}$ at the equator). As the previous metric was not available for marine areas, monthly averages of mean sea surface temperatures (from 1971 to 2000) were extracted from the NOAA Physical Sciences Division (http://www.esrl.noaa.gov/psd) and projected to the same grid. In grid cells of coastal areas, where both mean air temperature and mean sea surface temperature were available, we checked that the two measurements were correlated (see Figure S2.1 in Appendix S1). This allowed us to combine both temperature measurements (air and sea) to a single dataset of ocean and terrestrial monthly average temperatures. This is an important step to consider all migratory species in our analyses, including seabirds wintering at sea, which are usually excluded from analyses of climatic niches (e.g. Lavergne, Evans, Burfield, Jiguet, \& Thuiller, 2013; Pearman et al., 2013). As a further variable, we extracted temperature seasonality from the databases, defined as the amount of temperature variation over a given year (or averaged years) based on the standard deviation of monthly temperature averages (Hijmans et al., 2005).

\subsection{Comparative analyses of climatic niches}

We used four different metrics to characterize and compare species' thermal niches of breeding and wintering ranges (see Figure S2.3 in Appendix S1 for details).
1. First, we computed the mean temperature seasonality across each species' breeding range to test whether the experienced climate seasonality correlates with the species' migratory strategy and migration distance. Assuming that seasonality increases with increasing latitude, we also checked for a correlation between mean breeding latitude and migration strategies.

2. Second, to assess whether migratory species tend to track the same thermal conditions through the seasons, we computed the overlap between the temperature kernel density distributions of species' breeding and wintering ranges (Figure S2.3 in Appendix S1), based on the four summer and four winter months' temperatures of these two ranges respectively. This overlap was computed as the D-metric (Schoener, 1970), which ranges from zero (no overlap) to one (complete overlap).

3. Third, to quantify whether a species tends to spend the winter in a warmer or colder thermal niche, we calculated the difference between the 97.5 percentiles of the kernel density distribution of wintering and breeding temperatures. We used the 97.5 percentiles instead of an average value in order to characterize the maximum thermal niche, which may be the main driver of selection towards wintering under warmer climates.

4. Finally, we quantified how migration behaviour affects the experienced year-round thermal niche of each species by comparing the wintering ground and the hypothetical wintering on the breeding ground. To do so, we calculated the difference between the 97.5 (and 2.5) percentile of the density distributions of temperature values each species actually experiences in its breeding and wintering ranges all together ( 4 months in its breeding range +4 months in its wintering range) and the 97.5 (and 2.5) percentile of temperature values it would hypothetically experience if it was wintering and breeding in the same range (8 months in its breeding range). We term this last metric 'thermal niche change' (TNC, Figure S2.3 in Appendix S1). A positive value indicates that the migration behaviour shifts the thermal niche of a species towards overall higher temperatures.

Phylogenetic generalized least squares regressions (PGLS) were used to test for the linear relationships between the above four metrics of climatic niches as explanatory variables and migration strategies and distances as response variables. PGLS avoid pseudo-replication due to the relatedness of species by applying a phylogenetic correction ( $R$ package PHYLoLM, Ho \& Ane, 2014) through a lambda model of phylogenetic signal (Pagel, 1999). All models were fitted for all birds worldwide and then separately for the three focal orders Anseriformes, Charadriiformes and Passeriformes.

\subsection{Ancestral state reconstructions and inference of biogeographic scenarios}

Due to the distinct evolutionary history of the different bird clades of the world, the lability of the traits characterizing migration behaviour and the so far shifting relationships between major avian orders (Jarvis et al., 2014; Jetz et al., 2012; Prum et al., 2015), we 
did not perform an ancestral state reconstruction on all bird species but focused separately on the three focal orders Anseriformes, Charadriiformes and Passeriformes.

Ancestral state reconstructions of migratory strategies (resident, partial migrant, strict migrant) were performed using constant rate Markov Chain models (R package Diversitree, FitzJohn, 2012). We tested three different transition rate models: equal rates between all states (ER), different rates between all states (ARD) and different rates with the transition rate between resident and strict migrant constrained to zero (stepping-stone model, ST hereafter). The hypothesis underlying the ST model is that direct shifts from resident to strict migratory behaviour (and vice versa) are impossible, and lineages necessarily need to go through a state of partial migration containing both the strict migrant and resident fractions. The model yielding the lowest AIC value was selected and used for ancestral state reconstructions. Joint ancestral state reconstructions were used to assign the most likely migratory strategy to each internal node (FitzJohn, 2012). This allowed us to determine the most likely ancestral migration strategy of each study order. To quantify the accumulation of migratory lineages over time, we performed lineage-through-time plots for each order by assigning nodes to either a migratory strategy (strict and partial migrants combined) or a resident strategy.

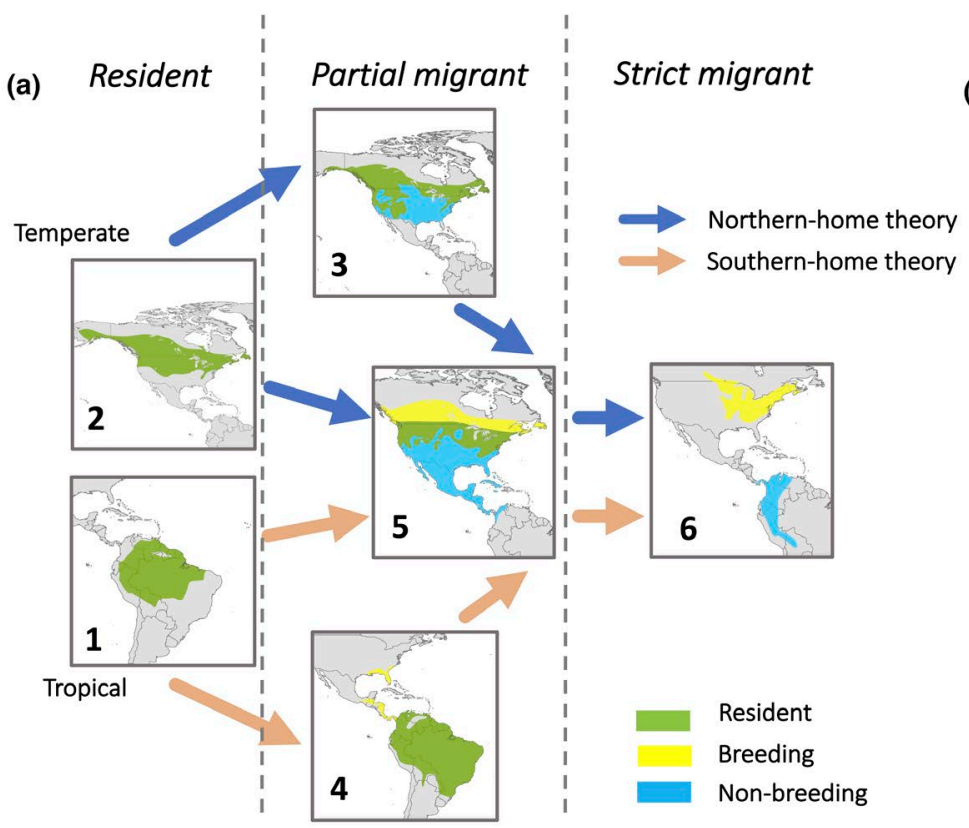

To test whether one of the biogeographic scenarios (NHT and SHT) better explains the evolutionary emergence of migration within the three studied orders, we performed additional ancestral state reconstructions using a more detailed set of states depicting species ranges, as residents, partial migrants and strict migrants, with reference to their latitudes of occurrence (see Figure 2a). The rationale of our approach is that particular combinations of transitions between these states correspond to the alternative NHT and SHT. To do this, we used the package Diversitree (FitzJohn, 2012, see Table S3.2b in Appendix S1) to select the best model (lowest AIC) depicting the data for each study clade, and to perform a 10,000-generation MCMC Bayesian inference (FitzJohn, 2012) to compute the posterior probability of each transition rate. We then combined the posterior distributions of different parameters to compute the posterior probability of each biogeographic scenario, that is $q_{2-5}+\left(q_{2-3} \times q_{3-5}\right)$ as an estimate of the probability of the NHT scenario, and $q_{1-5}+\left(a_{1-4} \times q_{4-5}\right)$ as an estimate of the probability of the SHT scenario (as depicted in Figure 2a; $a_{i-j}$ is the transition parameter between states $i$ and $j$ ). We estimated the difference between both scenario probabilities in each step of the MCMC chain to get the posterior distribution of credible values of the differences. We then assessed the statistical difference between scenario probabilities by checking whether the $95 \%$ credible interval of this distribution overlapped zero. (b)
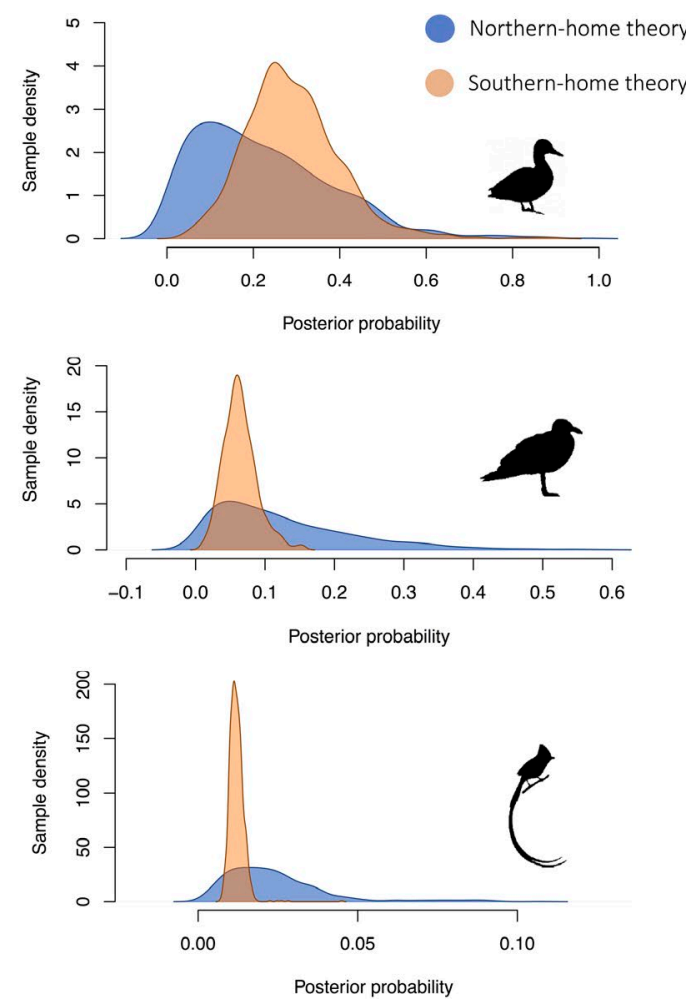

FIGURE 2 (a) Schematic modelling of the best Markov chain model explaining the evolution of migration behaviour under the biogeographic scenarios of NHT (blue arrows) or SHT (light red arrows). Different states of this model of evolution are pictured with distribution maps 1-6. Different ranges on maps are represented with standard bird handbook colours, that is, green for the distribution of sedentary birds, yellow for the breeding area and light blue for the wintering area of migratory birds. (b) Resulting posterior probabilities for NHT (blue) and SHT (light red) scenarios, based on the estimated transition rates of the best model, computed for Anseriformes, Charadriiformes and Passeriformes. Distribution kernels of posterior probabilities of NHT and SHT scenarios were calculated from 9,000 post-burnin MCMC samples of the best model [Colour figure can be viewed at wileyonlinelibrary.com] 


\section{3 | RESULTS}

\subsection{Comparative analyses of climatic niches}

Breeding range climatic seasonality was strongly associated with migratory strategies and distances (Figure 3). Residents experienced the lowest breeding range seasonality, while partial migrants bred under greater climatic seasonality and strict migrants under the highest seasonality. Within migratory species (partial and strict migrants), longdistance migrants had greater range seasonality than both short- and variable-distance migrants. As expected, similar patterns of correlation were found between strategy and distance of migration on the one hand and the mean breeding latitude on the other (Table S3.1 in Appendix S1 for statistical tests).

For both the global-scale analysis and for Passeriformes, we found that the thermal overlap between breeding and wintering ranges of partial and strict migrants was significantly lower than for resident species (Figure 4a, Table S3.1 in Appendix S1). We did not find any significant difference in the thermal niche overlap for Anseriformes and only between residents and strict migrants for Charadriiformes (Table S3.1 in Appendix S1), where the thermal overlap of strict migrants was significantly lower than for resident species. We also found an effect of the migration distance on the thermal niche overlap: both short- and long-distance migrants showed lower overlap values than variable-distance migrants at the global scale and for Charadriiformes and Passeriformes (Figure 4b, Table S3.1 in Appendix S1). However, for Anseriformes, long-distance migrants exhibited a higher thermal overlap than variable- and short-distance migrants.

The difference between the $97.5 \%$ quantiles of wintering and breeding temperatures showed that long-distance migrant species

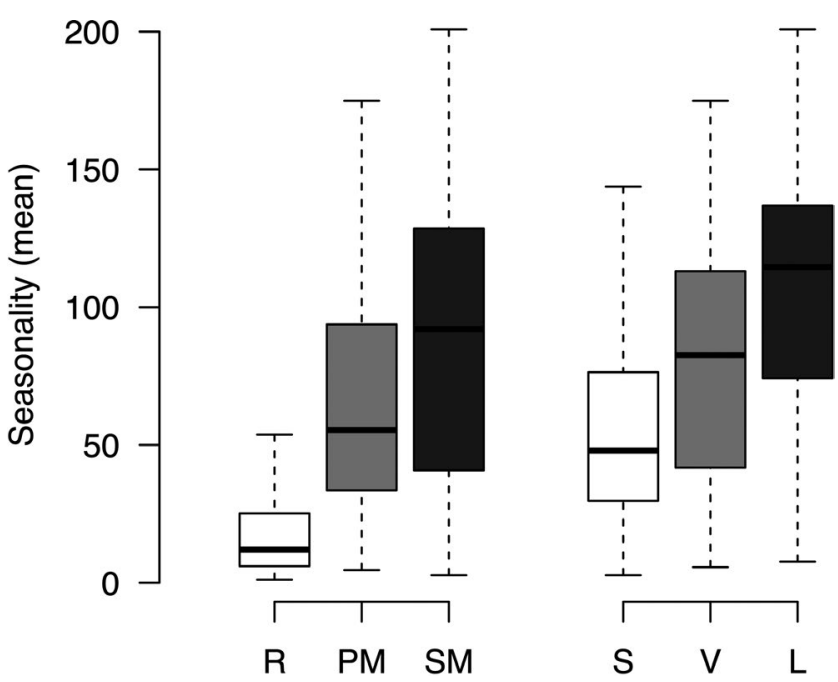

FIGURE 3 Relationships between the mean temperature seasonality (SD of monthly temperature averages) of species' breeding ranges and their migration characteristics. Migration strategy are resident (R), partial migrant (PM) and strict migrant (SM), and migration distance (right panel) are short distance (S), variable distance $(\mathrm{V})$ and long distance $(\mathrm{L})$ tended to migrate towards warmer environments during their nonbreeding period, when compared to their breeding temperatures (97.5\% temperature difference: $3.74^{\circ} \mathrm{C}$; Figure $4 \mathrm{c}$ ). In contrast, both variable- and short-distance migrant species, tended to migrate towards temperatures colder than those they experience in their breeding quarters $(97.5 \%$ temperature difference: -1.76 and $-4.21^{\circ} \mathrm{C}$, respectively; Figure $4 \mathrm{c}$ ). The same results were consistently found for the three study orders (Table S3.1 in Appendix S1).

Within migratory species, the change in species' thermal niche due to migration shows that the results for the shifts of the $2.5 \%$ and $97.5 \%$ percentiles of the temperature values were similar (Table S3.1 in Appendix S1): long-distance migrants showed the largest thermal niche change during migration by increasing both their thermal minima and maxima, followed by variable-distance migrants and short-distance migrants (Figure $4 \mathrm{~d}$ ). This pattern was strikingly consistent between the three main study orders, which showed the exact same difference of thermal niche changes between classes of migration distance (Figure 4d, Table S3.1 in Appendix S1).

\subsection{Ancestral state reconstructions and biogeographic scenarios}

Model selection for ancestral state reconstructions of migration strategies systematically rejected the equal rates model for the three studied bird orders (Table 1). For both Anseriformes and Charadriiformes, the stepping stone models were retained, with a root constrained to resident for Charadriiformes, and with no root constraint for Anseriformes (Table 1). Marginal likelihoods from models with an unconstrained root yielded a 0.76 and 0.34 posterior probability for a resident ancestor as an ancestor of Charadriiformes and Anseriformes respectively (see Figure 1a). For Passeriformes, the best model depicting the evolution of migration strategies was a model with all rates different and a root constrained to strict migrant (posterior probability of 0.62 ).

In Anseriformes, migratory behaviour seems to have first appeared around 6.6 Ma ago (Figure 1b), with the first node exhibiting migratory behaviour being the most recent common ancestor of the subfamily Anserinae (swans and true geese). This emergence was then followed by a rapid accumulation of migratory lineages during the Pleistocene. In Charadriiformes, ancestral state reconstructions suggested that the earliest appearance of migratory behaviour occurred around $22.5 \mathrm{Ma}$ ago (Figure 1b). The emergence of most migrant lineages was estimated to mainly occur during the Pliocene. Surprisingly, the ancestor of Passeriformes was estimated most likely as a strict migrant. The first return to a sedentary strategy was estimated to occur around 39.7 $\mathrm{Ma}$ and resident lineages became the dominant strategy within Passeriformes from mid-Oligocene (Figure 1b).

The biogeographic model excluding transitions 3-6 and 4-6 (and vice versa) best fitted our data (Figure $2 a$ ), and this model structure was then used to run MCMC sampling to estimate the relative probability of the two biogeographic scenarios of the origins of migration (NHT or SHT; Table S3.2c in Appendix S1). For all three orders, we found no support for any of the two biogeographic scenarios 
(a)
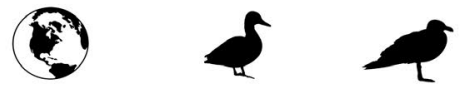

C
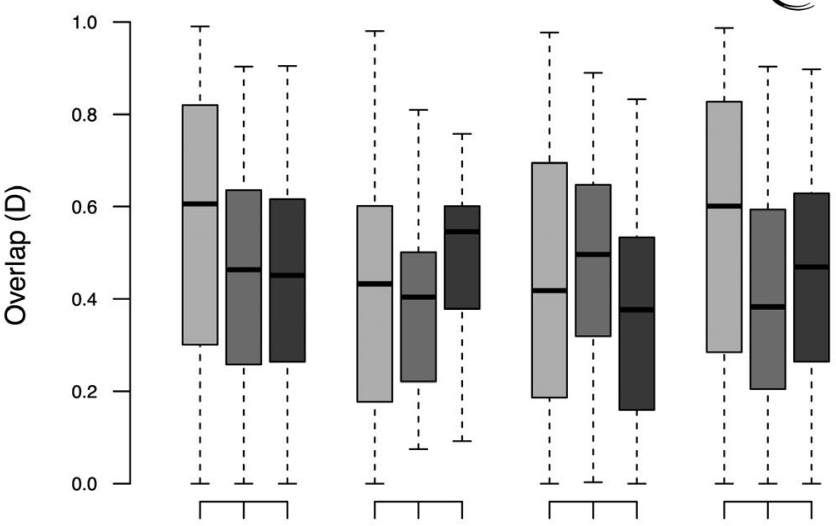

R PM SM
R PM SM
R $\mathrm{PM} S \mathrm{SM}$ Strategy

(c)
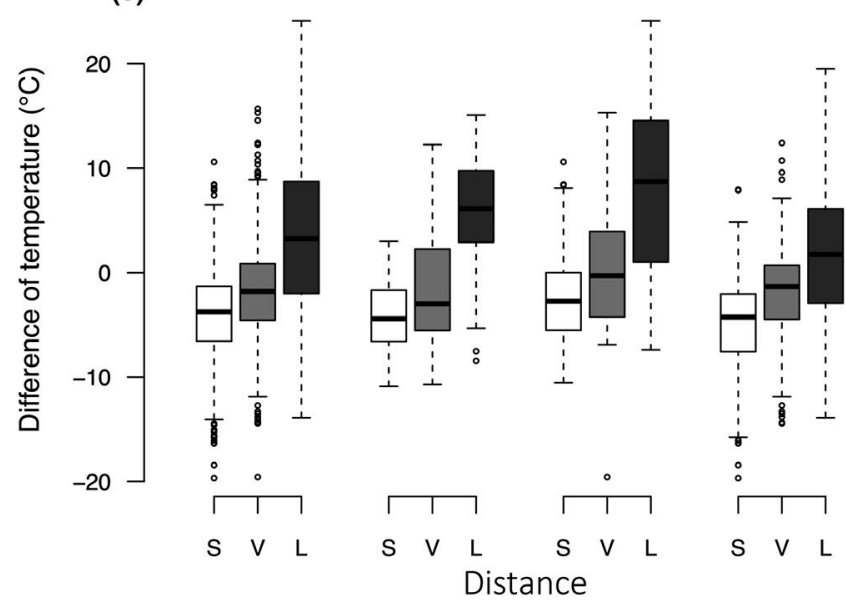

(b)
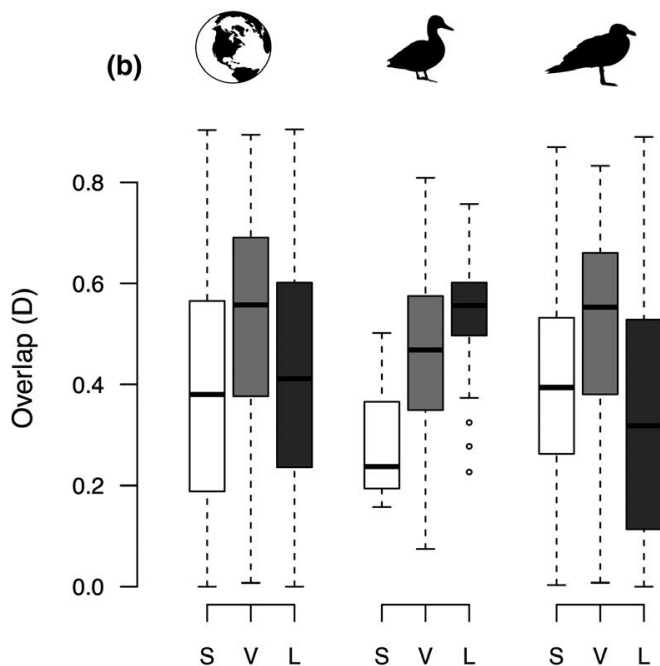

S V L

Distance
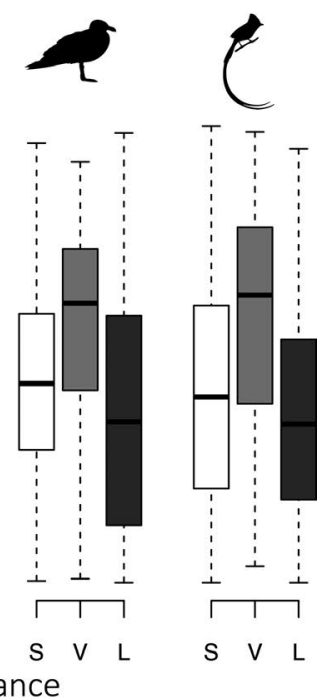

(d)
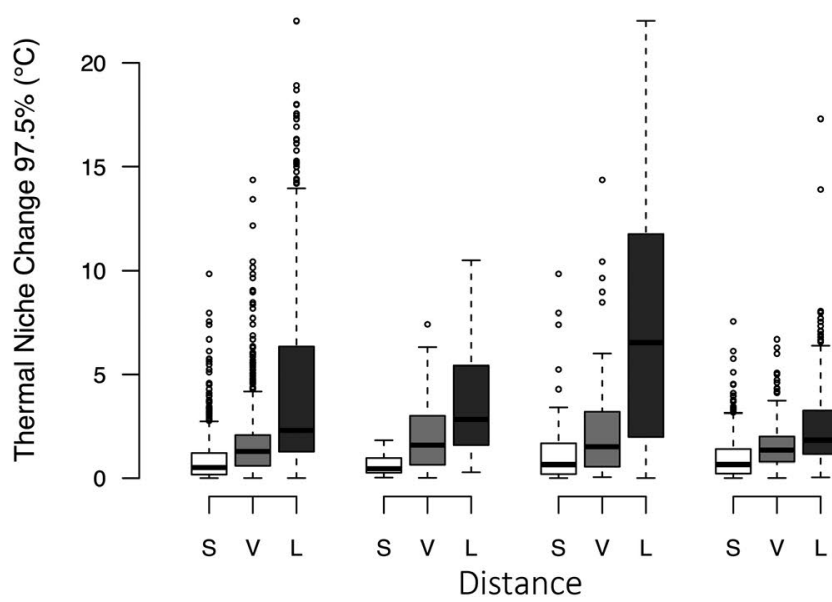

FIG URE 4 Boxplots showing (a) the overlap between temperatures of species' wintering and breeding ranges for each migration strategy; (b) the overlap between temperatures of species' wintering and breeding ranges for each class of migration distance; (c) the difference between the $97.5 \%$ temperature quantile in species wintering and breeding ranges for each class of migration distance; and (d) the difference between the $97.5 \%$ percentile of temperature values experienced by a migratory species (in its breeding and wintering range) and the $\mathbf{9 7 . 5 \%}$ percentile of temperatures it would hypothetically experience when staying year-round in its breeding range, for each class of migration distance. Each relationship is plotted for all bird species worldwide and for the three study orders, Anseriformes, Charadriiformes and Passeriformes

(Figure 2b). Indeed, while the modal value suggests emergences of migratory behaviour more frequently under a SHT scenario in Anseriformes ( 0.28 against 0.19 for $\mathrm{NHT}$ ) and under a NHT scenario in Charadriiformes (0.1 against 0.06 for SHT), these differences in probabilities are not statistically supported (95\% confidence interval for Charadriiformes: -0.106:0.352; Anseriformes: -0.457:0.403; Passeriformes: -0.011:0.034).

\section{4 | DISCUSSION}

Large-scale phylogenetic studies investigating the evolutionary origins of long-distance migration are very scarce (Winger et al., 2014).
Here we studied an almost unexplored area: the biogeographic and climatic context of the evolutionary emergence of long-distance bird migration worldwide (see Gomez et al., 2016).

While we think that case studies of particular clades with well-resolved phylogenies would provide more in-depth tests of the evolutionary origins of bird migration, large-scale analyses are equally important to provide generalization and to examine broad evolutionary hypotheses deeply rooted in the classical literature of bird migration. These hypotheses concern the link between migration and climatic seasonality, the different selection of climatic niches during breeding and non-breeding periods, as well as the past tempo and the geographic routes of emergence and loss of bird migration. 
TAB LE 1 Model selection for ancestral state reconstructions of migration strategies (resident, partial migrant, strict migrant) in large migratory orders of birds

\begin{tabular}{|c|c|c|c|c|c|c|c|c|c|c|}
\hline \multirow[b]{2}{*}{ Model } & \multirow[b]{2}{*}{ Nb parameters } & \multicolumn{3}{|c|}{ Anseriformes } & \multicolumn{3}{|c|}{ Charadriiformes } & \multicolumn{3}{|c|}{ Passeriformes } \\
\hline & & Log-lik & AIC & $\Delta \mathrm{AIC}$ & Log-lik & AIC & $\Delta \mathrm{AIC}$ & Log-lik & AIC & $\Delta \mathrm{AIC}$ \\
\hline ARD & 7 & -152.1 & 318.2 & 5.1 & -364.8 & 743.6 & 6.2 & -2159.0 & $4,332.0$ & 2.5 \\
\hline ARD.root1 & 6 & -152.1 & 316.2 & 3.1 & -364.6 & 741.2 & 3.8 & -2160.5 & $4,332.9$ & 3.5 \\
\hline ARD.root2 & 6 & -152.1 & 316.2 & 3.1 & -365.7 & 743.3 & 5.9 & -2159.5 & $4,331.0$ & 1.6 \\
\hline ARD.root3 & 6 & -152.1 & 316.2 & 3.1 & -367.8 & 747.7 & 10.3 & -2158.7 & $4,329.4$ & 0.0 \\
\hline ER & 2 & -169.1 & 342.2 & 29.1 & -403.9 & 811.8 & 74.4 & -2661.3 & $5,326.6$ & 997.2 \\
\hline ER.root1 & 1 & -169.1 & 340.2 & 27.1 & -403.9 & 809.8 & 72.4 & -2661.3 & $5,324.6$ & 995.2 \\
\hline ER.root2 & 1 & -169.1 & 340.2 & 27.1 & -403.9 & 809.8 & 72.4 & -2666.3 & $5,334.5$ & $1,005.1$ \\
\hline ER.root3 & 1 & -169.1 & 340.2 & 27.1 & -403.9 & 809.8 & 72.4 & -2666.3 & $5,334.5$ & $1,005.1$ \\
\hline ST & 5 & -152.6 & 315.2 & 2.0 & -364.9 & 739.8 & 2.4 & -2171.9 & $4,353.9$ & 24.5 \\
\hline ST.root1 & 4 & -152.6 & 313.2 & 0.0 & -364.7 & 737.4 & 0.0 & -2173.4 & $4,354.8$ & 25.3 \\
\hline ST.root2 & 4 & -152.6 & 313.2 & 0.0 & -365.7 & 739.5 & 2.1 & -2172.4 & $4,352.8$ & 23.4 \\
\hline ST.root3 & 4 & -152.6 & 313.2 & 0.0 & -367.9 & 743.8 & 6.4 & -2171.7 & $4,351.3$ & 21.9 \\
\hline
\end{tabular}

For each study order, models were compared using Akaike information criterion (AIC) scores; model likelihood and delta AIC relative to the best model are also given. Three models were tested: equal transition rates between all states (ER), different transition rates between all states (ARD), and models without direct transition between resident and strict migrant states (stepping stone model; ST). For each model, four different root constraints were tested: no constraint, constrained to resident (root1), constrained to partial migrant (root2), or constrained to strict migrant (root3). Models in bold were considered the best models following Akaike information criterion (AIC) selection.

\section{1 | Climatic seasonality has triggered the evolution of long-distance migration}

A primary result of our study is that birds' geographic migration likely evolved, at least in part, as a response to the onset of seasonal environments on a geologic time-scale (see Somveille, Rodrigues, et al., 2018; Winger et al., 2019). Although the link between species migration and relatively high latitudes was known (Somveille, Manica, Butchart, \& Rodrigues, 2013), this statistical link between long-distance migration and the strong climatic seasonality of birds' breeding ranges had never been regarded using phylogeny-based comparative analyses. In fact, despite the mostly temperate and Arctic latitudes of the breeding ranges of migratory species, this link between bird migration distances and the local climate of their breeding ranges is not trivial at all. For instance, the migration distances of species breeding in very seasonal local environments within temperate latitudes (between latitudes $50^{\circ}$ and $30^{\circ}$ and $-30^{\circ}$ and $-50^{\circ}$ ) are as long as, and sometimes longer tFFhan, the migration distances of some species breeding in Arctic latitudes (results not shown). In addition, many species breeding in highly seasonal mountain environments could escape climatic seasonality by travelling much shorter distances that they actually do (but see Laube et al., 2015). These results support the idea that strong climatic seasonality has been an important factor in the evolution of long-distance bird migration (see Winger et al., 2019; Zink \& Gardner, 2017). However, more in-depth studies are needed to confirm and understand the effect of different drivers on the evolution of long-distance migration, ideally by considering several environmental factors (see O'Connor et al., 2018; Somveille, Manica, et al., 2018) and by using clades with well-resolved phylogenies.

\section{2 | Long-distance migrants seek warmer niches during winter}

When considering all migratory species of the world, we found that partial and strict migrant species do not generally follow the same climatic niche year-round but rather spend winters in an environment warmer than that experienced in their breeding range ('niche switchers'). This result appears to somewhat contradict the results obtained by Somveille, Manica, et al. (2018), but are in agreement with the study by Laube et al. (2015) conducted on fewer species. Studies exploring the link between adaptive fitness costs or benefits and migration distances within a philopatric species of Charadriiformes (Limosa limosa) indeed show that wintering further south in Europe yields greater individual fitness (Alves et al., 2013) without any apparent flight cost (Kentie et al., 2017). These studies suggest that selection gradients may favour wintering areas in warmer areas in certain bird lineages. There are, however, notable exceptions to this general pattern of birds switching to warmer climates during their winter migration. These exceptions mainly concern Anseriformes, where strict migrants are more likely to be niche trackers than partial migrants and residents. These results call for complementary analyses testing whether the niche tracking or niche switching migration strategy could be linked to different life history traits such as parental care, reproductive investment, diet composition or foraging strategies.

Our results indicating that strict migrants, particularly Passeriformes, are mostly 'niche switchers' may seem odd in the light of two former studies conducted on smaller clades of Passeriformes and suggesting that migratory species are mostly 'niche trackers' between seasons (Gomez et al., 2016; Nakazawa et al., 2004). Here, 
based on the $97.5 \%$ quantiles of wintering and breeding temperatures, we found that the best predictor of the strategy of niche switching is migration distance (Figure $4 c, d$ ). Long-distance migrants tend to spent winter in warmer climate niches than species migrating over shorter distances, and this pattern was strikingly consistent across global and order-centred analyses. This is corroborated by another recent study suggesting a lack of overlap between climatic niches of breeding and wintering ranges of long-distance migrants on a subset of migratory species (Zurell et al., 2018). Moreover, a recent study found that species travelling intermediate geographical distances (corresponding to our variable-distance class) tend to be relatively good at tracking thermal conditions closely throughout the year and having moderate gains in terms of access to resources (Somveille, Manica, et al., 2018). It was also demonstrated that Sylvia warblers did not compensate for the flight costs of a longer migratory journey by tracking their more nearby climatic and land cover niches (Laube et al., 2015). Our results and, at least partly, recent literature suggests an important phenomenon about bird migration: the evolution of long-distance migration could be linked to a behaviour of seeking warmer climates in which to spend the non-breeding period.

Such a large-scale study obviously comes with limitations. One limitation certainly lies in the fact that climatic variability of species niches was only quantified in terms of temperature variations. There is evidence suggesting that several environmental factors (precipitation, NDVI, etc.) are relevant to bird demography (Somveille, Manica, et al., 2018), but nevertheless temperature alone has been identified as an important driver of bird distributions (Fort, Beaugrand, Grémillet, \& Phillips, 2012; Meehan, Jetz, \& Brown, 2004; Root, 1988). It is important to note that the aim of our study was to include all long-distance migrants of the avian class, as these are often omitted from global analyses (e.g. Somveille et al., 2013; Zurell et al., 2018), due to their partially or strictly oceanic range. Considering only birds' thermal niches was thus the only way to include species whose distribution range include oceanic environments at some moment of their annual cycle. Another limitation could come from the fact that we have classified the migration characteristics of birds into discrete classes, assuming a relatively shorter migration distance for year-resident tropical species. Future analyses that would take into account a more detailed value of the migration distance would certainly detect tighter links between the evolution of birds' migration distance and tracking of their climatic niche.

Another limitation could come from the fact that we have classified the migration characteristics of birds into discrete classes, including the migration distance, which is actually complex than three classes. Future analyses that would take into account a more detailed value of the migration distance would certainly detect tighter links between the evolution of the migration distance and the tracking of the climate niche.

\section{3 | Diverse biogeographic scenarios led to long- distance migration}

Our estimation of a resident ancestor of Anseriformes and Charadriiformes converges with previous studies realized on clades nested within these two orders. A study on the genus Charadrius (Charadriiformes) estimated a resident ancestor from South America (Joseph, Lessa, \& Christidis, 1999), whereas a possible resident ancestor of the Anatidae family (Anseriformes) was estimated from Afrotropical or Neotropical areas (Gonzalez, Düttmann, \& Wink, 2009). We did not find convincing statistical support to explain the emergence of a migratory behaviour indicating that migration did not evolve more often from tropical or temperate resident ancestors. However, our ancestral state reconstructions suggest that migration could have appeared in Anseriformes lineages more frequently from tropical locations, whereas migration could have appeared more frequently in Charadriiformes lineages from temperate areas. Nevertheless, the estimation of a resident ancestor and a tropical origin for the Anatidae family, to which most Anseriformes migratory species belong, may be consistent with a hypothetical southern-home appearance of migration behaviour. The lack of a clear delimitation between the NHT and SHT scenarios suggests that, as shown by Winger et al. (2014), this type of modelling approach from distribution maps shows interesting patterns in the evolution of bird migration but is probably more powerful for detecting recent scenarios of evolution. Recent changes in bird species' distributions and adjustments of their migration behaviour (see for example Able $\&$ Belthoff, 1998) may have masked signatures of biogeographic movements in deeper nodes of the phylogenetic trees of study orders.

While we highlighted the emergence of seasonal migration behaviour and its repeatability across time and space, we also found evidence for several episodes of loss of migration behaviour. This suggests that in the past migratory lineages may have adapted to novel ecological opportunities by returning to a resident state. This reasoning is supported by Kondo, Peters, Rosensteel, and Omland (2008) who demonstrated that sedentary and subtropical species may be secondary drop offs of temperate long-distance migrants (see also Bruderer \& Salewski, 2008; Winger, Lovette, \& Winkler, 2012). They indeed showed that the subtropical short-distance migrant, the black-backed oriole (Icterus galbula), diverged recently from the temperate breeding long-distance migrant, the Baltimore oriole (Icterus abeillei). They suggested that the latter maintained long-distance migration throughout the last glacial episodes, and that a founder population of the black-backed oriole reduced migratory distance by using an unoccupied niche (Kondo et al., 2008). More generally, this was suggested by the study of Rolland, Jiguet, Jønsson, Condamine, and Morlon (2014), which showed that migration triggered speciation when migratory lineages settled down to become resident. Moreover, the better fit of the stepping stone model and the low transition rates observed between resident and strict migrant states indicate that the partial migrant state is probably a necessary evolutionary step between strict residence and strict migration. Altogether this suggests a high flexibility in the proportions of migratory behaviour within populations over time (Bruderer \& Salewski, 2008). It would be interesting to consider, in the future, the wide variety of non-breeding movements in resident species (especially in the tropics) and dispersal movements (natal and breeding dispersal; Campbell \& Lack, 1985) to better understand the 
gradual appearance of a strict migratory behaviour between seasona habitats.

\subsection{Ancestral migratory strategies and timing of emergence}

The possibility of an ancestral migratory behaviour (strict migrant) in Passeriformes is somewhat surprising considering the large number of resident species within this order (more than $85 \%$ ), but the marginal likelihood of the unconstrained model clearly favoured a strict migrant strategy as an ancestral state. The lack of a well-resolved phylogeny for Passeriformes invites caution in the interpretation of this result. It is also important to note that considering migration strategies as discrete classes did not impact our results since we found an ancestral migratory behaviour despite the existence of a large number of tropical species that were all assumed to be sedentary in our analyses. Our finding of ancestral migratory behaviour in Passeriformes suggests that the large number of resident species observed today could result from repeated losses of migratory behaviour in the evolutionary history of this clade. It also makes sense in the light of the biogeographic history of the clade (see Bruderer \& Salewski, 2008; Ericson et al., 2002): Claramunt and Cracraft (2015) showed that part of the Passeriformes (suborder Tyranni, currently 1,000 species) probably diversified in South America, whereas the other part (suborder Passeri, currently 5,000 species) probably diversified later in the east of the Gondwana continent (Australia and New Guinea). Thus, an ancestral migratory character would have favoured the spread of this order across the globe during its diversification, positing that migratory behaviour could have allowed the exploration of different continents and niches. In addition, it should be noted that among the first fossils of Passeriformes discovered in the Northern hemisphere and dating from the late Oligocene and early Miocene, only one of them could be assigned to an extant family: that of Alaudidae (Ballmann, 1972), which is currently composed of many migratory species. Similarly, the first fossils of the North American continent containing Passeriformes are species considered close relatives to families of migratory birds (i.e. Passerellidae; Steadman, 1981).

The emergence date of migration behaviour was estimated at different times between study orders: in the upper Miocene for Charadriiformes, in the lower Miocene for Anseriformes and in the middle Eocene for Passeriformes. The appearance of migration behaviour in the Miocene for Charadriiformes and Anseriformes is consistent with a marked decrease in global temperatures and a concomitant reduction in the area of tropical biomes (see Bruderer \& Salewski, 2008). The estimated increase in the number of migratory species and the strong correlations observed between breeding seasonality and migration characteristics (strategy and distance) indicate that global cooling of the lower Oligocene had probably triggered the emergence of migratory species and lineages (see also Claramunt \& Cracraft, 2015; Louchart, 2008). Under this new emerging global climate, it seems that migration had then become a successful life history strategy for persistence under seasonal climates and may have allowed greater speciation rates (Rolland et al., 2014; Winger et al., 2012). Under such a biogeographic scenario, Passeriformes would have thus benefited from an early opportunity with ancestors already adapted to geographic migrations, allowing them to take advantage of the global cooling and fragmentation of tropical biomes to diversify into the many ecological niches left vacant.

\section{5 | CONCLUSIONS AND PERSPECTIVES}

Our results provide a large-scale test of how climatic niches and their year-round variability correlate with different aspects of bird migration, such as distance and the proportion of migrant and resident populations. We also report a correlation between long-distance migration and the tendency of birds to seek warmer climates during their non-breeding period, compared to short-distance migrants. Beyond that, we also infer an ancestral migratory behaviour in the deep evolutionary history of the Passeriformes order, which currently dominates the avian class. This result is consistent with an ancestral large diffusion of the clade around the globe (Ericson et al., 2002) and the fact that migration triggered speciation when migratory lineages settled down to be resident (Rolland et al., 2014). This leads to a prediction that would be interesting to test in the future: that long-distance migration behaviour not only allowed higher speciation rates but also faster rates of evolution of ecological niches.

\section{ACKNOWLEDGEMENTS}

We thank Andrea Kreit for her initial contribution to this project. This work was initiated thanks to the Aurora mobility grant, awarded by the French and Norwegian research councils. This work has been supported by a PhD grant to P.D. awarded by the LabEx OSUG@2020 (Investissements d'avenir - ANR10LABX56). Most computations presented in this paper were performed using the CIMENT infrastructure (https://ciment.ujf-grenoble.fr), which is supported by the Rhône-Alpes region (GRANT CPER07_13 CIRA: http://www.ci-ra. org) and France-Grille (http://www.france-grilles.fr).

\section{DATA AVAILABILITY STATEMENT}

Some data are publicly available; bird range maps at www.birdl ife.org, climate data at www.worldclim.org and http://www.esrl. noaa.gov/psd and bird phylogenetic data at www.birdtree.org. A table containing all species' migration characteristics is available in Supporting Information.

\section{ORCID}

Paul Dufour (iD https://orcid.org/0000-0002-7940-9997

Sébastien Descamps (iD https://orcid.org/0000-0003-0590-9013

Wilfried Thuiller (iD https://orcid.org/0000-0002-5388-5274 


\section{REFERENCES}

Able, K. P., \& Belthoff, J. R. (1998). Rapid "evolution" of migratory behaviour in the introduced house finch of eastern North America. Proceedings of the Royal Society B, 265, 2063-2071. https://doi. org/10.1098/rspb.1998.0541

Alerstam, T., Hedenström, A., \& Åkesson, S. (2003). Long-distance migration: Evolution and determinants. Oikos, 103, 247-260. https://doi. org/10.1034/j.1600-0706.2003.12559.x

Alves, J. A., Gunnarsson, T. G., Hayhow, D. B., Appleton, G. F., Potts, P. M., Sutherland, W. J., \& Gill, J. A. (2013). Costs, benefits, and fitness consequences of different migratory strategies. Ecology, 94, 11-17. https://doi.org/10.1890/12-0737.1

Alves, J. A., Gunnarsson, T. G., Potts, P. M., Gélinaud, G., Sutherland, W. J., \& Gill, J. A. (2011). Overtaking on migration: Does longer distance migration always incur a penalty? Oikos, 121, 464-470. https://doi. org/10.1111/j.1600-0706.2011.19678.x

Ballmann, P. (1972). Les oiseaux miocènes de Vieux-Collonges (Rhône). Documents du Laboratoire de Géologie de la Faculté des Sciences De Lyon, 50, 93-101.

Bell, C. P. (2000). Process in the evolution of bird migration and pattern in avian ecogeogaphy. Journal of Avian Biology, 31, 258-265.

BirdLife International \& NatureServe (2017). Bird species distribution maps of the world. Version 2.0. Cambridge, UK/Arlington, IL: BirdLife International/NatureServe.

Bruderer, B., \& Salewski, V. (2008). Evolution of bird migration in a biogeographical context. Journal of Biogeography, 35, 1951-1959. https:// doi.org/10.1111/j.1365-2699.2008.01992.x

Campbell, B., \& Lack, E. (1985). A dictionary of birds. Calton, UK: T\& A.D. Poyser.

Claramunt, S., \& Cracraft, J. (2015). A new time tree reveals Earth history's imprint on the evolution of modern birds. Sciences Advances, 1, e1501005. https://doi.org/10.1126/sciadv.1501005

Cooney, C. R., Bright, J. A., Capp, E. J. R., Chira, A. M., Hughes, E. C. Moody, C. J. A., ... Thomas, G. H. (2017). Mega-evolutionary dynamics of the adaptive radiation of birds. Nature, 542, 344-347. https:// doi.org/10.1038/nature21074

Cox, G. W. (1968). The role of competition in the evolution of migration. Evolution, 22, 180.

Egevang, C., Stenhouse, I. J., Phillips, R. A., Petersen, A., Fox, J. W., \& Silk, J. R. D. (2010). Tracking of Arctic terns Sterna paradisaea reveals longest animal migration. Proceedings of the Natural Academy of Sciences of the USA, 107, 2078-2081. https://doi.org/10.1073/pnas.09094 93107

Ericson, P. G. P., Christidis, L., Cooper, A., Irestedt, M., Jackson, J., Johansson, U. S., \& Norman, J. A. (2002). A Gondwanan origin of passerine birds supported by DNA sequences of the endemic NewZealand wrens. Proceedings of the Royal Society B, 269, 235-241. https:// doi.org/10.1098/rspb.2001.1877

FitzJohn, R. G. (2012). Diversitree: Comparative phylogenetic analyses of diversification in R. Methods in Ecology \& Evolution, 3, 1084-1092.

Fort, J., Beaugrand, G., Grémillet, D., \& Phillips, R. A. (2012). Biologging, remotely-sensed oceanography and the continuous plankton recorder reveal the environmental determinants of a seabird wintering hotspot. PLoS ONE, 7, e41194. https://doi.org/10.1371/journ al.pone.0041194

Gauthreaux, S. A. (1982). The ecology and evolution of avian migration systems. Journal of Avian Biology, 6, 93-168.

Gomez, C., Tenorio, E. A., Montoya, P., \& Cadena, C. D. (2016). Nichetracking migrants and niche-switching residents: Evolution of climatic niches in New World warblers (Parulidae). Proceedings of the Royal Society B, 283, 20152458. https://doi.org/10.1098/ rspb.2015.2458

Gonzalez, J., Düttmann, H., \& Wink, M. (2009). Phylogenetic relationships based on two mitochondrial genes and hybridization patterns in Anatidae. Journal of Zoology, 279, 310-318. https://doi. org/10.1111/j.1469-7998.2009.00622.x

Gwinner, E., \& Helm, B. (2003). Circannual and circadian contributions to the timing of avian migration. In P. Berthold, E. Gwinner, \& E. Sonnenschein (Eds.), Avian migration (pp. 81-95). Berlin, Germany: Springer.

Hijmans, R. J., Cameron, S. E., Parra, J. L., Jones, P. G., \& Jarvis, A. (2005). Very high resolution interpolated climate surfaces for global land areas. International Journal of Climatology, 25, 1965-1978. https:// doi.org/10.1002/joc.1276

Ho, L. S. T., \& Ane, C. (2014). A linear-time algorithm for Gaussian and non-Gaussian trait evolution models. Systematic Biology, 63, 397408. https://doi.org/10.1093/sysbio/syu005

Del Hoyo, J., Elliott, A., Sargatal, J., Christie, D. A., \& de Juana, E. (Eds.) (2018). Handbook of the birds of the world alive. Barcelona: Lynx Edicions. Retrieved from http://www.hbw.com/

Jarvis, E. D., Mirarab, S., Aberer, A. J., Li, B., Houde, P., Li, C., ... Zhang, G. (2014). Whole-genome analyses resolve early branches in the tree of life of modern birds. Science, 346, 1320-1331. https://doi. org/10.1126/science.1253451

Jetz, W., Thomas, G. H., Joy, J. B., Hartmann, K., \& Mooers, A. O. (2012). The global diversity of birds in space and time. Nature, 491, 444-448. https://doi.org/10.1038/nature11631

Joseph, L., Lessa, E. P., \& Christidis, L. (1999). Phylogeny and biogeography in the evolution of migration: Shorebirds of the Charadrius complex. Journal of Biogeography, 26, 329-342. https://doi.org/ 10.1046/j.1365-2699.1999.00269.x

Joseph, L., \& Stockwell, D. (2000). Temperature-based models of the migration of Swainson's flycatcher (Myiarchus swainsoni) across South America: A new use for museum specimens of migratory birds. Proceedings of the Academy of Natural Sciences of Philadelphia, 150, 293-300

Kentie, R., Marquez-Ferrando, R., Figuerola, J., Gangoso, L., Hooijmeijer, J. C. E. W., Loonstra, A. H. J., ... Piersma, T. (2017). Does wintering north or south of the Sahara correlate with timing and breeding performance in black-tailed godwits? Ecology and Evolution, 7, 28122820. https://doi.org/10.1002/ece3.2879

Kondo, B., Peters, J. L., Rosensteel, B. B., \& Omland, K. E. (2008). Coalescent analyses of multiple loci support a new route to speciation in birds. Evolution, 62, 1182-1191. https://doi.org/ 10.1111/j.1558-5646.2008.00345.x

Laube, I., Graham, C. H., \& Boehning-Gaese, K. (2015). Niche availability in space and time: Migration in Sylvia warblers. Journal of Biogeography, 42, 1896-1906.

Lavergne, S., Evans, M. E. K., Burfield, I. J., Jiguet, F., \& Thuiller, W. (2013). Are species' responses to global change predicted by past niche evolution? Philosophical Transactions of the Royal Society B, 368, 20120091-20120091. https://doi.org/10.1098/rstb.2012.0091

Levey, D. J., \& Stiles, F. G. (1992). Evolutionary precursors of long-distance migration: Resource availability and movement patterns in neotropical landbirds. The American Naturalist, 140, 447-476. https:// doi.org/10.1086/285421

Louchart, A. (2008). Emergence of long distance bird migrations : A new model integrating global climate changes. Naturwissenschaften, 95, 1109-1119. https://doi.org/10.1007/s00114-008-0435-3

Martínez-Meyer, E., Peterson, A. T., \& Navarro-Sigüenza, A. G. (2004). Evolution of seasonal ecological niches in the Passerina buntings (Aves: Cardinalidae). Proceedings of the Royal Society B, 271, 1151-1157.

Meehan, T. D., Jetz, W., \& Brown, J. H. (2004). Energetic determinants of abundance in winter landbird communities. Ecology Letters, 7, 532537. https://doi.org/10.1111/j.1461-0248.2004.00611.x

Nakazawa, Y., Peterson, A. T., Martínez-Meyer, E., \& Navaroo-Siguenza, A. G. (2004). Seasonal niches of migratory birds : Implications for the evolution of migration. The Auk, 121, 610-618. 
Newton, I. (Ed.) (2008). The migration ecology of birds. London, UK Elsevier.

O'Connor, E. A., Cornwallis, C. K., Hasselquist, D., Nilsson, J.-Å., \& Westerdahl, H. (2018). The evolution of immunity in relation to colonization and migration. Nature Ecology \& Evolution, 2, 841-849. https:// doi.org/10.1038/s41559-018-0509-3

Pagel, M. (1999). Inferring the historical patterns of biological evolution. Nature, 401, 877-884. https://doi.org/10.1038/44766

Pearman, P. B., Lavergne, S., Roquet, C., Wüest, R., Zimmermann, N. E., \& Thuiller, W. (2013). Phylogenetic patterns of climatic, habitat and trophic niches in a European avian assemblage. Global Ecology and Biogeography, 23, 414-424. https://doi.org/10.1111/geb.12127

Prum, R. O., Berv, J. S., Dornburg, A., Field, D. J., Townsend, J. P., Moriarty Lemmon, E., \& Lemmon, A. R. (2015). A comprehensive phylogeny of birds (Aves) using targeted next-generation DNA sequencing. Nature, 526, 569-573. https://doi.org/10.1038/nature15697

Pulido, F. (2007). The genetics and evolution of avian migration. BioScience, 57, 165-174. https://doi.org/10.1641/B570211

Rappole, J. H. (Ed.) (1995). The ecology of migrant birds: A neotropical perspective. Washington, DC: Smithsonian Institution Press.

Rappole, J. H. (Ed.) (2013). The avian migrant. New York, NY: Columbia University Press, pp. 5-7

Rolland, J., Jiguet, F., Jønsson, K. A., Condamine, F. L., \& Morlon, H. (2014). Settling down of seasonal migrants promotes bird diversification. Proceedings of the Royal Society B, 281, 20140473-20140473. https://doi.org/10.1098/rspb.2014.0473

Root, T. (1988). Energy constraints on avian distributions and abundances. Ecology, 69, 330-339. https://doi.org/10.2307/1940431

Salewski, V., \& Bruderer, B. (2007). The evolution of bird migration-A synthesis. Naturwissenschaften, 94, 268-279. https://doi.org/ 10.1007/s00114-006-0186-y

Schoener, T. W. (1970). Nonsynchronous spatial overlap of lizards in patchy habitats. Ecology, 51, 408-418. https://doi.org/10.2307/1935376

Somveille, M., Manica, A., Butchart, S. H. M., \& Rodrigues, A. S. L. (2013). Mapping global diversity patterns for migratory birds. PLoS ONE, 8, 1-10. https://doi.org/10.1371/journal.pone.0070907

Somveille, M., Manica, A., \& Rodrigues, A. S. L. (2018a). Where the wild birds go: Explaining the differences in migratory destinations across terrestrial bird species. Ecography, 42(2), 225-236. https://doi. org/10.1111/ecog.03531

Somveille, M., Rodrigues, A. S. L., \& Manica, A. (2018b). Energy efficiency drives the global seasonal distribution of birds. Nature Ecology and Evolution, 2, 962-969. https://doi.org/10.1038/s41559-018-0556-9

Somveille, M., Rodrigues, A. S. L., \& Manica, A. (2015). Why do birds migrate? A macroecological perspective. Global Ecology and Biogeograhy, 24, 664-674. https://doi.org/10.1111/geb.12298

Steadman, D. W. (1981). A re-examination of Palaeostruthus hatcheri (Shufeldt): A late Miocene sparrow from Kansas. Journal of Vertebrate Paleontology, 1, 171-173.

Winger, B. M., Auteri, G. G., Pegan, T. M., \& Weeks, B. C. (2019). A long winter for the red queen: Rethinking the evolution of seasonal migration. Biological Reviews, 94, 737-752. https://doi.org/10.1111/brv.12476
Winger, B. M., Barker, F. K., \& Ree, R. H. (2014). Temperate origins of longdistance seasonal migration in New World songbirds. Proceedings of the National Academy of Sciences of the USA, 111, 12115-12120. https:// doi.org/10.1073/pnas.1405000111

Winger, B. M., Lovette, I. J., \& Winkler, D. W. (2012). Ancestry and evolution of seasonal migration in the Parulidae. Proceedings of the Royal Society B, 279, 610-618. https://doi.org/10.1098/ rspb.2011.1045

Zink, R.M.(2002). Towards a framework for understanding the evolution of avian migration. Journal of Avian Biology, 33, 433-436. https://doi.org/ 10.1034/j.1600-048X.2002.03081.x

Zink, R. M., \& Gardner, A. S. (2017). Glaciation as a migratory switch Sciences Advances, 3, e1603133. https://doi.org/10.1126/ sciadv.1603133

Zurell, D., Gallien, L., Graham, C. H., \& Zimmermann, N. E. (2018). Do long-distance migratory birds track their niche through seasons? Journal of Biogeography, 45, 1459-1468. https://doi.org/10.1111/ jbi.13351

\section{BIOSKETCHES}

Paul Dufour is an experienced field ornithologist, and PhD candidate with broad interests in the evolution of long-distance bird migration, at different taxonomic scales.

Co-authors are researchers with interests in population biology, macroecology and macroevolution of biodiversity.

Author contributions: S.L., K.S., S.D. and P.D. conceived the ideas. J.R. collected and gridded the distribution maps and the climatic data. S.L., K.S., S.C., S.D., W.T. and P.D. developed the methods. M.G. and P.D. ran the analyses. P.D. and S.L. wrote the first version of the paper and all authors contributed substantially to the revisions.

\section{SUPPORTING INFORMATION}

Additional supporting information may be found online in the Supporting Information section at the end of the article.

How to cite this article: Dufour P, Descamps S, Chantepie S et al. Reconstructing the geographic and climatic origins of long-distance bird migrations. J Biogeogr. 2020;47:155-166. https://doi.org/10.1111/jbi.13700 